\title{
Profissionalização de pessoas com deficiência: Reflexões e possíveis contribuições da psicologia
}

\author{
Professionalization of disabled people: Reflections and possible \\ contributions from psychology \\ La profesionalización de las personas con discapacidad: Reflexiones y \\ posibles contribuciones de la psicología
}

\author{
Camila Mugnai VIEIRA ${ }^{1, a}$ \\ Priscila MugnaiVIEIRA ${ }^{\mathrm{b}}$ \\ Ieda FRANCISCHETTI ${ }^{a}$ \\ Faculdade de Medicina de Marília, Marília, SP, Brasil ${ }^{2}$, Universidade Federal de São Carlos, São Carlos, SP, Brasil ${ }^{\mathrm{b}}$
}

ResumO o fenômeno da profissionalização de pessoas com deficiência é complexo e perpassa as contradições os desafios para a profissionalização de pessoas com deficiência elencam-se: postos precários, informais, baixa ou nenhuma remuneração, baixas escolaridade e qualificação técnica. A legislação traz avanços, porém o cumprimento é frágil e reducionista. Este trabalho apresenta possibilidades de contribuições da psicologia nos diferentes contextos: junto aos sujeitos com deficiências e seus familiares, à comunidade empresarial, às instituições e à sociedade civil, por meio da educação. Discute-se o tema expondo as limitações a partir dos diferentes sujeitos sociais e as contradições que coexistem nas políticas públicas, mas, sobretudo, aponta-se caminhos e propõe-se na psicologia importantes instrumentos para a inclusão.

Palavras-chave:

Pessoas com deficiência; capacitação professional; emprego.

Abstract The phenomenon of professionalization of disabled people is complex and goes beyond the contradictions of the capitalist system, social structure and interactions, behavior and the human psyche. Among the professionalization challenges for people with disabilities, we list the following: insecure and informal positions, minimal or no compensation, low education and qualifications. Legislation brings advances but its compliance is fragile and reductionist. This paper presents potential contributions from psychology, through education, in different contexts: together with disabled persons and their families, the business community, institutions, and civil society. We discuss the professionalization of people with disabilities; the limitations are exposed considering the different social subjects and the contradictions that exist in public policies. But mainly, direction is offered and important instruments in psychology are proposed for greater inclusion.

Keywords:

Disabled persons; professional training; employment.

Resumen El fenómeno de la profesionalización de las personas con discapacidad es complejo y va más allá de las contradicciones del sistema capitalista, de la estructura y de las interacciones sociales, de las conductas y del psiquismo humano. Entre los desafíos para la profesionalización de las personas con discapacidad destacan: los empleos precarios e informales, la baja o nula remuneración, el bajo nivel educativo y de cualificación técnica. La legislación trae avances pero su cumplimiento es frágil y reduccionista. El presente trabajo presenta posibles contribuciones de la psicología, a través de la educación, a diferentes contextos: las personas con discapacidad y sus familias, la comunidad empresarial, las instituciones y la sociedad civil. Discute el tema exponiendo las

\footnotetext{
1 Endereço para correspondência: Faculdade de Medicina de Marília, Ambulatório de Saúde Mental, Avenida Monte Carmelo, - até 410/411, Fragata, Marília, SP, Brasil 17501360. Telefone: (14) 34021844. Email:camilamugnai@ hotmail.com
} 
limitaciones a partir de los diferentes sujetos sociales y las contradicciones que coexisten en las políticas públicas, pero, sobre todo, apunta caminos y propone, en la psicología, importantes instrumentos para la inclusión.

Palabras-clave:

Personas con discapacidad; capacitación profesional; empleo.

$\mathrm{O}$ fenômeno da profissionalização de pessoas com deficiência é complexo e multifacetado, uma vez que se insere nas contradições do sistema capitalista, na estrutura social por ele organizada e perpassa ainda questões relacionadas à dinâmica e funcionamento do psiquismo humano e das interações sociais estabelecidas nos diversos contextos. Desse modo, trata-se de uma temática que ainda precisa ser demasiadamente refletida, discutida e aprofundada por diferentes áreas do conhecimento.

De acordo com a Declaração Universal dos Direitos Humanos, emitida pelas Nações Unidas em 1948, o trabalho é um direito fundamental de todos os seres humanos. Além de garantir a sobrevivência, contribui para o bem-estar emocional, satisfaz o desejo de sentir-se produtivo e reconhecido socialmente. Dejours (1991) ressalta que o trabalho colabora para a satisfação de necessidades não apenas econômicas, mas também psicológicas e sociais. A psicodinâmica do trabalho indica que este não é redutível a uma atividade de produção no mundo objetivo, mas carrega a oportunidade de transformar o sujeito, pois gera a possibilidade de inserção social e relações interpessoais, que levam ao reconhecimento dos outros e pelos outros e ao aprimoramento da subjetividade.

Apesar das mudanças nas legislações e em algumas práticas, a representação das pessoas com deficiência ainda costuma relacioná-las à incompletude, incapacidade, dependência e patologia. Ainda são vistas, muitas vezes, como desviantes em todos os aspectos e não têm oportunidades de desenvolver sua independência. Algumas pessoas entendem que por terem uma limitação cognitiva ou física, por exemplo, elas apresentam restrições emocionais, afetivas, sexuais, laborais e sociais.

Diante desta realidade, ainda excludente, a inserção no mercado de trabalho significa ao sujeito com deficiência mais do que habitualmente representa às demais pessoas da sociedade, pois indica especial possibilidade de sair desta posição de estigmatizado, excluído e desacreditado socialmente para um papel produtivo em sua comunidade. Ademais, significa a oportunidade de aprendizado, independência e autonomia, gera novas perspectivas para sua vida, pois passa a ter uma remuneração e o reconhecimento ligado a uma categoria ocupacional, o que modifica sua identidade pessoal e social. Na família, perde a alcunha de "peso", pode pensar em um relacionamento afetivo mais duradouro, ampliam-se as oportunidades de contato social, o desenvolvimento de novas habilidades, entre outros.

Assim, frente às parcas ofertas de emprego às pessoas com deficiência, o valor de cada vaga conquistada representa "a oportunidade de uma nova vida" e isso explica a grande dedicação com que elas desempenham suas atividades. Souza-Silva, Diegues e Carvalho (2012) pontuam que o trabalho significa um novo espaço de socialização do sujeito e gera recompensas simbólicas, como valorização pessoal, efetivação do direito ao trabalho, contribuição na renda familiar e construção de uma identidade social.

Os resultados de Gomes (2009) reafirmaram a importância do trabalho na vida das pessoas com deficiência, sobretudo como forma de fortalecimento, reconstrução de sua identidade e valorização, ao se tornarem membros ativos da família, tanto no plano emocional quanto financeiro. Carvalho-Freitas, Toledo, Nepomuceno, Suzano e Almeida (2010) observaram que o trabalho era o aspecto central na vida de todas elas, estando, para algumas, mais relacionado à sobrevivência e, para outras, à inserção social. As vivências no trabalho estão ligadas ao sentimento de utilidade para com a sociedade, exercício de cidadania.

\section{Principais desafios para a profissionalização de pessoas com deficiência}

Atualmente, vive-se um conflito entre as necessidades das pessoas em relação ao trabalho, as exigências do mercado e as oportunidades de emprego formal para a população. Segundo o IBGE, a taxa de desocupação em julho de 2015 foi estimada em 7,5\% para o conjunto das seis regiões metropolitanas pesquisadas (Recife, Salvador, Belo Horizonte, Rio de Janeiro, São Paulo e Porto Alegre), representando aproximadamente 1,8 milhões de pessoas (IBGE, 2015).

Segundo o Censo de 2010, do IBGE, o Brasil tem mais de 44 milhões de pessoas com algum tipo de deficiência. Os dados apontam para um pouco mais do que 20 milhões de pessoas com deficiência ocupadas. Do total de trabalhadores com deficiência, verifica-se a predominância dos classificados com deficiência física 
(54,47\%), seguida dos auditivos (22,49\%), visuais (5,79\%), mentais (5,10\%) e deficiências múltiplas (1,26\%). Já segundo o Ministério do Trabalho e Emprego, por meio da Relação Anual de Informações Sociais (RAIS), em 2010, de aproximadamente 44 milhões de vínculos formais registrados, apenas 306.013 foram exercidos por trabalhadores com deficiência - apenas $0,7 \%$ do total) (IBGE, 2010). As pessoas com deficiência continuam concentradas em ocupações precárias e em sua maioria informais, como os trabalhadores sem carteira, por conta própria ou não remunerados. Aproximadamente $60 \%$ das pessoas com deficiência estavam em uma dessas três categorias em 2010, enquanto 45\% da população total encontravam-se nestas (IBGE, 2010). Portanto, a inserção das pessoas com deficiência no mercado de trabalho ainda é pouco expressiva.

Avanços vêm ocorrendo desde 1991, a partir da criação da chamada Lei de Cotas, art. 93 da Lei n. 8.213/91, ação afirmativa dentre outras que vêm sendo implementadas por meio de políticas públicas, fruto de décadas de reivindicações e movimentos sociais diversos na área das deficiências. Trata-se da obrigatoriedade estabelecida pela legislação para empresas com cem (100) ou mais empregados que deve preencher uma parcela de seus cargos com pessoas com deficiência. A cota depende do número geral de empregados que a empresa tem no seu quadro, na seguinte proporção: I - de 100 a 200 empregados, 2\%; II - de 201 a 500, 3\%; III - de 501 a 1.000 , 4\% e IV - de 1.001 em diante, 5\% (MTE, 2007).

Há uma série de questionamentos que podem ser feitos em relação às ações afirmativas e a esta Lei, no sentido de não poderem ser tratadas como fim, mas sim como meio de ampliação de oportunidades de acesso. Concomitantemente a elas, precisam ocorrer investimentos na melhoria da educação e outras ações, que em longo prazo tornem desnecessárias medidas como cotas, uma vez que todos possam ter acesso aos mesmos bens e oportunidades.

O que se observa atualmente é que a Lei de Cotas tem contribuído para ampliação do acesso de pessoas com deficiência ao mercado de trabalho. No entanto, ainda há dificuldades em razão da pouca fiscalização às empresas, que insistem em não cumprir a legislação. A justificativa dada por boa parte dos gerentes e/ou empresários está relacionada à baixa qualificação das pessoas com deficiência para o mercado de trabalho, o que dificulta que encontrem profissionais em condições de desempenhar de forma competente as funções necessárias à sua empresa.

Bittencourt e Fonseca (2011) pontuaram que as cotas não possibilitaram o acesso pleno desta população, uma vez que há nela o predomínio de baixa escolaridade e pouca qualificação profissional. Nascimento e Miranda (2007) destacaram que existe a necessidade de maior escolaridade e profissionalização, visto que o acesso ao mercado de trabalho exige níveis elevados de escolaridade e o desenvolvimento de novas competências para que a qualificação esteja em consonância com as necessidades do empregador.

Assim, ainda são disponibilizadas poucas vagas às pessoas com deficiência e, quando surgem, o processo de recrutamento e seleção apresenta problemas. Os critérios estabelecidos não são claros e as exigências não condizem com as necessidades apresentadas pelos candidatos, tornando as vagas inacessíveis à maioria dos sujeitos com deficiência. A maior parte das empresas apenas disponibilizam vagas para evitar as multas e buscam preenchê-las com um "deficiente perfeito", ou seja, um indivíduo que não apresente praticamente nenhuma limitação significativa, apenas alguma condição mínima que permita que ele seja considerado deficiente para preencher a cota, e que tampouco exija qualquer modificação do ambiente de trabalho ou tarefa ou um acompanhamento intenso de seu desempenho no cargo.

Violante e Leite (2011) apontaram que as políticas empresariais priorizaram contratações de pessoas cujas deficiências não exigiam transformações estruturais no ambiente de trabalho, esperando que o próprio indivíduo se ajustasse às condições das empresas e não o contrário. Em parte, é possível compreender o posicionamento das empresas, que vivem um dilema entre manter sua alta produtividade e lucro, em função das demandas do mercado capitalista, e atender à legislação que se propõe à inclusão.

Diante deste dilema, a adoção de ações afirmativas e a diversidade no ambiente de trabalho podem diferenciar determinadas empresas no próprio mercado. Isto por meio do marketing social, pois há uma tendência de os consumidores procurarem produtos e práticas benéficas ao meio ambiente e à comunidade. A responsabilidade social passa a ser vista pelas empresas como uma estratégia para aumentar seu lucro e desenvolvimento (Pires, Bonfim, \& Bianchi, 2007).

Os estudos indicam que algumas empresas realizam a contratação de pessoas com deficiência apenas em função da Lei de Cotas e não estão comprometidas com a empregabilidade dessa clientela. Neste sentido, Hansel (2009) evidenciou que muitas organizações ainda desconhecem a proposta da Lei de Cotas, bem como 
as ações exigidas para garantir a acessibilidade ao trabalhador. Algumas empresas relataram que precisaram atender à legislação sob pena de multa, desconhecendo a importância de promover adaptações que levassem ao sucesso das pessoas com deficiência na organização. Tanaka e Manzini (2005) também apontaram que a contratação nas empresas estudadas em sua pesquisa ocorreu, predominantemente, pela obrigatoriedade da lei. Em contrapartida, as pesquisas indicaram que os gestores das organizações que contrataram essas pessoas, de um modo geral, estão satisfeitos com a inclusão desses sujeitos, e relataram que eles trouxeram benefícios para a empresa, principalmente em relação à sua imagem e à responsabilidade social (Hansel, 2009).

Outro elemento que perpassa a postura de grande parte das companhias é a representação social da pessoa com deficiência, ainda ligada à improdutividade, incompetência e dependência. As concepções de deficiência ainda se relacionam unicamente a patologias ou características e comportamentos individuais desviantes e permeiam o universo do trabalho, de tal sorte que contratar uma pessoa com deficiência é algo impensável e, quando obrigatório, é evitado ao máximo, por parecer excessivamente dispendioso. De acordo com Toldrá, Marques e Brunello (2010), as principais dificuldades para a inclusão de pessoas com deficiência no mercado de trabalho, sob a perspectiva de instituições especializadas, são decorrentes da desinformação da sociedade sobre a deficiência, o que gera atitudes preconceituosas, além da distância entre as exigências das empresas e o nível de formação e escolarização dos indivíduos, aspecto já citado.

Quando ocorre a contratação, frente a tantos vieses, o trabalhador com deficiência já é tratado de modo diferenciado e negativo e responde de acordo com este tratamento. As fragilidades do seu desempenho são ressaltadas em detrimento de suas potencialidades, sendo inclusive utilizadas para confirmar as expectativas negativas a seu respeito. A própria pessoa com deficiência também compartilha dessas representações em alguns casos. Sua autoimagem e sua autoestima são construídas a partir das relações sociais vivenciadas em seu contexto. Quando ainda predominam concepções negativas, as chances de as pessoas com deficiência terem menos oportunidades de desenvolvimento pessoal e de perceberem-se negativamente aumentam. Esses fenômenos intensificam-se quando os familiares também compartilham este olhar.

A questão da família é demasiado complexa, pois envolve sentimentos desde o nascimento de uma criança com deficiência até expectativas, diagnósticos, luto, buscas por tratamentos, inúmeras emoções e mecanismos mentais para lidar com esta condição, que podem incluir a negação da deficiência ou a superproteção do indivíduo, restringindo-o ao ambiente familiar ou às instituições especializadas, considerando mais suas limitações que potencialidades (Barbosa, Balieiro, \& Pettengill, 2012). Considerar a possibilidade de a pessoa com deficiência trabalhar pode significar para ela e para a família um desafio imenso, pois leva à exposição pública de suas fragilidades, à necessidade de investimento em aprendizados e a experiências de separação muitas vezes inéditas.

Acrescenta-se às dificuldades para a inserção das pessoas com deficiência no mercado de trabalho a questão do Benefício de Prestação Continuada (BPC), que é um direito garantido pela Constituição Federal (CF) e consiste no pagamento de um salário mínimo mensal a pessoas com 65 anos de idade ou mais e a pessoas com deficiência incapacitante para a vida independente e para o trabalho, com renda per capita familiar inferior a um quarto do salário mínimo.

No Brasil, de modo geral, a condição de deficiência pode estar associada a situações de pobreza e exclusão. Assim, o BPC parece ser importante para a subsistência de muitas pessoas com deficiência e suas famílias. A perda deste benefício, substituído por um salário quase sempre baixo, somada a todos os desafios apresentados pela inserção do indivíduo no mercado formal de trabalho, faz com que alguns sujeitos e familiares não busquem a iniciativa de profissionalização. Apesar de não haver estudos indicando que o benefício seja motivador para a carência de mão de obra de pessoas com deficiência, este argumento é apresentado por diversos empresários (Pereira \& Passerino, 2012).

Dentre os fenômenos que dificultam a inserção das pessoas com deficiência no mercado de trabalho, a educação e a qualificação para o trabalho são fundamentais. O governo criou a Lei de Cotas, porém eximiu-se da responsabilidade de capacitação dessas pessoas, que há tanto tempo estão à margem do processo educacional e do mundo do trabalho. É como se naturalmente pudessem tornar-se aptas a funções que nunca exerceram ou como se o esforço individual bastasse para sua adaptação, ou seja, o sujeito precisa adequar-se ao ambiente e não o contexto modificar-se para a inclusão.

As empresas têm responsabilidade no treinamento e desenvolvimento de todos os seus empregados, inclusive aqueles com deficiência, porém, entende-se que isso deve ocorrer após sua entrada na organização. 
Para que as pessoas com deficiência consigam concorrer às vagas, serem aprovadas e mais, continuarem em seus empregos com desempenho satisfatório, faz-se essencial um preparo prévio, que deve incluir diversos elementos educacionais, laborais e sociais para sua formação.

É possível afirmar que, de acordo com a legislação brasileira atual, os alunos com deficiência devem frequentar o ensino comum, recebendo atendimento especializado como um apoio, mas a simples colocação de alunos na sala comum não representa sua real inclusão. Deve-se buscar atender ao máximo as suas necessidades, procurando os melhores recursos para cada caso, sendo urgente a reestruturação das escolas em diferentes níveis, como curriculares, estruturais, culturais, de formação e capacitação profissional.

Cordeiro (2013) aponta o acesso ainda incipiente de pessoas com deficiência à educação profissional, relacionado aos critérios seletivos para matrícula nos cursos, principalmente aqueles ligados ao nível de escolaridade dos alunos. Assim, a escolarização das pessoas com deficiência permanece precária, aspecto apontado por muitos empregadores como um obstáculo da contratação destes sujeitos (Bittencourt \& Fonseca, 2011).

As pessoas com deficiência ainda frequentam, em sua maioria, centros especializados, que também deveriam ocupar-se de sua formação para o trabalho. O que se observa, porém, é que este investimento não é realizado adequadamente na maior parte das instituições. Geralmente são desenvolvidas oficinas, não apenas as terapêuticas, mas as chamadas protegidas, que deveriam levar à profissionalização e até à geração de renda. Os estudos indicam que as atividades realizadas por estas geralmente oficinas não contribuem para inclusão dessas pessoas no mundo do trabalho, pois em sua maioria realizam apenas atividades simples, repetitivas, desvinculadas das demandas do mercado de trabalho, apresentando-se fragmentadas, produzindo um trabalho alienante e sem utilidade posterior (Meletti, 2001). É obvio que transformações ocorreram e que há diversas exceções e trabalhos diferenciados ocorrendo em algumas instituições brasileiras, mas ainda são pontuais, e as experiências que se destacam em sua maioria e aparecem nas pesquisas não tem contribuído para profissionalização dos sujeitos e sua inclusão social.

Em suma, as principais dificuldades na inserção de pessoas com deficiência no mercado de trabalho foram destacadas por Tanaka e Manzini (2005), segundo a percepção de empregadores, em quatro elementos: (a) da própria pessoa com deficiência: falta de escolaridade, de interesse e de qualificação profissional e social; (b) da empresa: condições inadequadas do ambiente físico e social, pouco conhecimento sobre a deficiência; (c) das instituições especializadas: programas de treinamento profissional e social ineficazes, pouca articulação com as empresas; e (d) do governo: dificuldades no acesso à escola e ao transporte e pouco incentivo às empresas para as adaptações e iniciativas de responsabilidade social.

Diante das dificuldades apontadas, estudos indicaram que as pessoas com deficiência que estão inseridas no mercado de trabalho apresentavam sentimentos ambivalentes com relação às suas experiências no contexto laboral. Além de incluírem sentimentos de satisfação e realização, relacionados especialmente à construção da identidade social de trabalhadores, há indícios de sofrimento no trabalho.

Leão e Silva (2012) investigaram as vivências subjetivas de indivíduos com deficiências auditivas e físicas de uma empresa de grande porte e concluíram que as vivências de sofrimento desses sujeitos sobrepõem-se às de prazer no trabalho e que a concepção de deficiência que prevalece dificulta seu crescimento profissional e inclusão ao ofício. Os resultados apontaram aspectos de sofrimento no trabalho advindos do desgaste físico ou psíquico e da falta de reconhecimento, que geraram estratégias defensivas frente às adversidades. Souza-Silva et al. (2012) apontaram que o sentimento de dignidade advindo da inserção no mercado de trabalho permite ao sujeito sair do lugar de vitimização, porém tem repercussões ambíguas em seu psiquismo, pois essas pessoas só tiveram acesso ao trabalho a partir de uma imposição legal, o que lhes atribui uma condição de heteronomia.

Coelho (2009) investigou o significado do emprego para 30 pessoas com deficiência inseridas no mercado de trabalho e as dificuldades e estratégias utilizadas no cotidiano da atividade, que se apresentou como organizador da vida, estruturador da identidade e gerador de prazer e sofrimento, que se manifestou em situações de altas demandas externas e internas, conflitos entre trabalho prescrito e real, concorrência e desvalorização. Neste estudo, porém, perceberam-se atitudes mais resilientes por parte dos indivíduos. A principal estratégia utilizada foi reconhecer e compartilhar capacidades e necessidades, o que contribuiu para minimizar as dificuldades.

Sugere-se melhor equacionamento dos processos de gestão na organização, considerando a percepção desses trabalhadores, a ressignificação das concepções de deficiência, o cumprimento da lei e cuidado à saúde mental destes sujeitos (Leão \& Silva, 2012). Toda e qualquer intervenção que pretenda colaborar com a 
inclusão de pessoas com deficiência no mercado de trabalho não pode desconsiderar os aspectos políticos, econômicos e sociais apontados até o momento. Ações isoladas terão pouca efetividade, sendo fundamental a articulação de mudanças nestes diferentes âmbitos, propostas intersetoriais e trabalhos que envolvam equipes multiprofissionais. De tal sorte que se enfatiza a importância de políticas públicas efetivas, fiscalização quanto ao cumprimento da legislação, investimento em educação de qualidade para todos nos diferentes níveis, criação de centros de qualificação profissional articulados ao mercado de trabalho atual, que visem atividades que possam ser generalizadas inclusive em outras situações de ocupação, não apenas aquelas para as quais são treinados (Meletti, 2001), adequação dos ambientes físicos e demais estruturas para garantir acessibilidade, entre outros. Ressalta-se que as transformações necessárias não ocorrerão rapidamente, pois se tratam de processos, inseridos em contextos complexos, como já descrito. De todo modo, precisam ser disparados e acelerados na medida do possível, com planejamentos e iniciativas exequíveis, pois não acontecerão naturalmente.

\section{Possíveis contribuições da psicologia}

Dentre os vários profissionais que podem contribuir com estas ações, o psicólogo pode desempenhar importante papel, em diversas esferas e linhas de ação, sempre em parceria com outros profissionais das áreas de saúde, educação, administração, arquitetura e serviço social, por exemplo. O psicólogo atua em diferentes contextos, de acordo com sua formação e demandas: clínicas, serviços de saúde, escolas, empresas, espaços comunitários, entre outros. Independente do cenário de atuação e da especialidade deste profissional, a categoria é pautada em princípios éticos sólidos que respaldam as intervenções, sempre no sentido do bem estar das pessoas, respeito aos direitos humanos e à diversidade, além de um compromisso social com mudanças que levem a uma sociedade inclusiva. A atuação do psicólogo pode ser pensada em três linhas de ação principais, desenvolvidas em diferentes contextos, como clínicas, serviços comunitários e de saúde, instituições de ensino e empresas: (a) junto às pessoas com deficiência, (b) junto às famílias e (c) no contexto social.

A partir do momento em que o sujeito com deficiência expõe-se aos desafios e às dificuldades no meio social mais amplo, incluindo o mercado de trabalho, suas chances de desenvolver suas potencialidades tendem a ser aumentadas e, conforme avança nesse processo, pode buscar uma melhor qualificação, tornando-se capaz de responder às exigências sociais e de reivindicar seus direitos (Ribeiro \& Lima, 2010). De tal sorte que são essenciais ações que fortaleçam e apoiem estes indivíduos nesta empreitada.

A despeito da importância das ações voltadas ao meio social, as pessoas com deficiência ainda apresentam demandas e necessidades de intervenções voltadas para si, que auxiliem em seu desenvolvimento comportamental, social e laboral. Nesse sentido, o psicólogo pode atuar no desenvolvimento de situações de treinamento de habilidades para a empregabilidade, que englobam desde atividades da vida diária, como estabelecer e seguir uma rotina, noções de tempo e espaço, que incluem horários, locomoção e acesso aos meios de transporte, organização de seus objetos e atividades, compreender e seguir regras, assumir responsabilidades, entre outras. Estas ações podem incluir acesso a informações, mas especialmente intervenções no ambiente natural em que serão realizadas, que envolvem aproximações sucessivas com a atividade, esquemas de reforço positivo, ensino colaborativo e tutorias.

A especificidade das ações do psicólogo neste âmbito deve-se a intervenções mais terapêuticas, que podem incluir desde sessões de psicoterapias individuais ou grupais, oficinas que ofereçam atividades com o mesmo fim, acompanhamento terapêutico nas ações cotidianas, entre outros. Em todas as ações é fundamental que seja considerada a demanda do sujeito, além daquelas do seu entorno ou da instituição ou empresa, por exemplo. Desse modo, todo projeto terapêutico deve ser singular, planejado e voltado às necessidades daquele indivíduo, que terá histórias de vivências particulares, que podem envolver traumas diversos ou expressões atuais de sintomas, somatizações ou fobias, por exemplo, que se referem particularmente ao âmbito da saúde mental.

O foco de todo o trabalho deve pautar-se no desenvolvimento do bem estar físico e emocional do sujeito e visar o máximo de sua autonomia e independência, além da melhoria de sua autoimagem, autoestima e autoconfiança. Estes aspectos muitas vezes estão comprometidos em sujeitos com deficiências, em função das representações sociais ainda vigentes e do processo de exclusão social vivenciado. Assim, é fundamental trabalhá-los, algumas vezes iniciando, por exemplo, pela própria imagem e cuidados com a aparência destas pessoas, que irá refletir na visão que os outros terão de sua competência (Omote, 1990). Como todas as ações em psicologia devem considerar o sujeito envolvido, para o planejamento e desenvolvimento destas intervenções 
é preciso inicialmente escutar todas as pessoas, criar oportunidades para que expressem seus desejos, angústias, demandas conscientes e inconscientes.

Outro trabalho possível é especificamente voltado à orientação profissional. Em função das poucas ofertas de vagas de emprego às pessoas com deficiência, comumente elas parecem não ter escolha quanto ao que querem fazer em termos profissionais, tendo que submeter-se ao que aparecer. Novamente respeitando o sujeito para além da condição da deficiência, é possível desenvolver um trabalho que possibilite por meio de entrevistas e testes projetivos, entre outros instrumentos, o levantamento de habilidades e interesses destes indivíduos, que se relacionam com áreas de atuação profissional específicas, o que poderia ampliar as chances de sucesso em sua atuação no mercado de trabalho, além de sua satisfação.

É óbvio que não se pode ignorar as raras oportunidades de emprego que são oferecidas, de tal forma que ações visando o treino funcional para atividades específicas são importantes, além de todo acompanhamento deste sujeito desde a seleção, inserção, adaptação ao cargo, avaliações de desempenho. O apoio nestes momentos de mudança, estresse e angústia podem fortalecer o sujeito a enfrentá-los com menos sofrimento e maior confiança, ampliando as chances de sucesso. Ele precisa ter clareza das atividades que deve desempenhar, das expectativas a seu respeito e do que envolve o processo de trabalho. É a empresa que deve proporcionar-lhe isso, por meio, por exemplo, de seu profissional psicólogo. Tette, Carvalho-Freitas e Oliveira (2013) destacam que a organização deve fornecer informações adequadas, disponibilizar materiais, cumprir as obrigações financeiras e realizar as adaptações estruturais necessárias, gerar um clima de confiança e apoio para que as pessoas com deficiência possam reconhecer suporte no ambiente e, assim, construir um sentido para seu trabalho.

A esfera das relações interpessoais e da comunicação mostra-se fundamental no ambiente de trabalho. Algumas pessoas com deficiência, por terem seu ambiente restrito apenas à família e a instituições especiais, podem apresentar dificuldades nas interações relacionadas a diferentes habilidades, desde a percepção da fisionomia dos outros, por exemplo, à expressão de suas ideias e dúvidas. A avaliação e o treino de habilidades sociais podem ser extremamente úteis junto a esta população.

As habilidades sociais referem-se ao conjunto de desempenhos apresentados pelo sujeito diante de demandas de situações interpessoais, que podem ser caracterizados com base em fatores pessoais, situacionais e culturais, que influenciam sua competência social e interações com as demais pessoas. Consiste em clarear quais são as competências já desenvolvidas pelo indivíduo e quais requerem atenção e intervenção específica em diferentes âmbitos, como comportamentos verbais e não verbais (expressar afetos, iniciar, manter e encerrar uma conversação, pedir/dar feedback, justificar-se, solicitar/prestar ajuda, opinar, agradecer, manter contato visual, gesticular, por exemplo), componentes cognitivos-afetivos (como empatia, leitura do ambiente, resolução de problemas, auto-observação, conhecimento sobre os papéis sociais e cultura), além de componentes fisiológicos (aparência pessoal, respiração, batimentos cardíacos, etc.).

A avaliação do repertório social referente ao desempenho manifesto e encoberto deve considerar a frequência das habilidades apresentadas, sua funcionalidade e adequação às ocasiões e consequências obtidas, dificuldade atribuídas ao desempenho de habilidades específicas e importância dada pelo sujeito ou pessoas significantes a desempenhos de habilidades específicas. O Treino de Habilidades Sociais (TSH) pode ser aplicado individualmente ou em grupo e deve prever um planejamento que contemple: objetivos, sequência e duração das sessões, procedimentos de avaliação e de intervenção (Del Prette \& Del Prette, 1999). Este treino pode contribuir para o melhor desempenho no trabalho e nas interações sociais, diminuir estigmas e preconceitos em relação à pessoa em função de melhores relações sociais e, ainda, melhorar sua autoimagem e expectativas sobre si mesma (Campos, 2006).

A família consiste em referência para o desenvolvimento de todos os sujeitos. Independentemente de sua constituição e dinâmica, que atualmente apresentam uma diversidade de possibilidades, a família sempre influencia a personalidade e a vida dos indivíduos. As famílias podem reagir de diferentes formas ao fato de terem uma pessoa com deficiência em sua constelação. Podem apresentar ações positivas e de resiliência, atitudes de superproteção, que levam à dependência extrema destes sujeitos, ou ainda depreciação e descrédito pelos próprios familiares. Sejam quais forem as reações, as famílias precisam ser escutadas e incluídas no processo de profissionalização destas pessoas.

Como aponta Hansel (2009), a família precisa de suporte psicológico e oportunidade de participar de orientações sobre as potencialidades e limitações do seu filho para a inserção no mundo do trabalho, o que pode contribuir para o desenvolvimento da autonomia do seu familiar com deficiência. É necessário que se 
considerem as demandas específicas de cada família e dos sujeitos de maior importância nas relações de cuidado e/ou interação com a pessoa com deficiência e assim delimitem-se as intervenções, que podem incluir orientações individuais ou coletivas, psicoterapias para casais, para o grupo familiar, grupos operativos e/ou de ajuda mútua de pais, mães e/ou irmãos, entre outras ações, mediadas pelo psicólogo.

Deve-se buscar o fortalecimento destas famílias, no sentido de conhecerem e lutarem por seus direitos, cumprirem seus deveres, ampliarem sua autoestima e autoconfiança, sentirem-se mais seguras com os processos de mudança (Barbosa et al., 2012).

É essencial que os familiares de pessoas com deficiência sejam esclarecidos, possam refletir sobre o processo e tomar decisões autônomas conscientes, como por exemplo, abrir mão do BPC para a contratação de seu filho, ou permitir que este pegue sozinho o ônibus para o trabalho, exponha-se às seleções, avaliações, demissões ou outras situações de frustração até então evitadas. É necessário que a família tenha um espaço para expressar suas angústias, compartilhar suas experiências e fortalecer-se no processo. A família também é essencial no desenvolvimento de ações cotidianas no ambiente doméstico, que podem contribuir com as intervenções desenvolvidas pelo psicólogo no treino de habilidades sociais e de empregabilidade. Deve ser incentivada, por exemplo, a criar e seguir regras de horário, divisão de tarefas que incluam a pessoa com deficiência, estímulos para que esta assuma responsabilidades e seja independente, orientando-a a realizar uma atividade, depois a acompanhando e posteriormente, permitindo que realize sozinha.

Quando se trata de ações no âmbito social, há uma infinidade de possibilidades a serem pensadas para a atuação do psicólogo, desde ações em instituições de ensino, que abordem professores e funcionários, em centros comunitários variados, em espaços públicos como teatros, praças, cinemas, bem como em empresas ou locais de trabalho especificamente. A necessidade de intervenções desta natureza deve-se especialmente às concepções ainda vigentes sobre as pessoas com deficiência, que incluem representações estereotipadas, que levam a ações preconceituosas. Nascimento e Miranda (2007) ressaltam a necessidade de mais informações sobre as pessoas com deficiência, destacando suas habilidades, com objetivo de diminuir o estigma e a discriminação ainda existentes que geram resistências na contratação desta população. De acordo com Sassaki (2006), são fundamentais ações de sensibilização e capacitação para melhorar os comportamentos e atitudes de colegas, empregadores e familiares, que repercutem na exclusão deste trabalhador.

A psicologia social pode colaborar especialmente com seu conhecimento sobre a formação de atitudes sociais e, especificamente, estratégias de mudanças das mesmas, enfocando particularmente atitudes em relação às pessoas com deficiência e à inclusão. Há procedimentos variados baseados na criação de condições nas quais a manipulação de componentes cognitivos, afetivos e/ou comportamentais leva as pessoas a vivências e conhecimentos que contrariam suas crenças e sentimentos em relação ao objeto atitudinal, sendo estes modificados e apresentados mais positivamente (Omote, Oliveira, Baleotti, \& Martins, 2005).

A oportunidade de experiências de contato com pessoas com deficiência tem o potencial de tornar as atitudes sociais mais favoráveis, pois estas passam a ser vistas enquanto sujeitos e não apenas por sua condição desviante, a interação face-a-face permite que se conheça não apenas suas limitações, mas suas potencialidades, seus anseios e sentimentos, oque pode levar à identificação de similaridades entre eles e os que não têm deficiências, e maior aproximação e valorização. Este contato, no entanto, precisa ser mediado e bem trabalhado para que resulte em vivências benéficas para ambos os lados. Pesquisas têm mostrado que empresários que já contratam pessoas com deficiência estão satisfeitos com sua atuação e tendenciosos a mais contratações futuras (Hansel, 2009).

Alguns fenômenos relatados em pesquisas da área da psicologia social devem ser considerados nestas ações, gerando estratégias como: (a) ampliar a visibilidade de pessoas com deficiência em todos os contextos, como na mídia, em espaços públicos, para que não sejam mais considerados como "estranhas". Ações de grupos artísticos de teatro e música, por exemplo, que fazem apresentações públicas, destacam as habilidades de pessoas com deficiência e são importantes estratégias de mudanças de atitudes sociais; (b) visar assegurar nas relações, quando possível, igualdade de status entre as pessoas com e sem deficiência, por exemplo, entre funcionários de um mesmo setor, todos devem ter a mesma importância; (c) considerar cuidadosamente as necessidades especiais que demandam apoios e ou adaptações e disponibilizar recursos, equipamentos e serviços necessários à acessibilidade destas pessoas, ou seja, a deficiência não pode ser negada em nome de uma distorção do discurso "politicamente correto" de serem todos iguais; (d) ao mesmo tempo, destacar as habilidades e potencialidades destes sujeitos para além de limitações específicas; e (e) realizar estratégias específicas junto às pessoas do 
entorno, que podem melhorar atitudes sociais, como possibilitar o acesso a informações por parte de comunicadores respeitados pela audiência, gerar oportunidades de compartilhar ideias sobre o tema em grupos e de expressá-las publicamente. A partir do momento que eu faço uma palestra sobre inclusão, por exemplo, a chance de eu comportar-me de acordo, aumenta. $\mathrm{O}$ investimento de tempo, dinheiro e energia em um assunto, aumenta a possibilidade de eu tornar-me favorável em relação a ele.

Quando eu invisto em retirar barreiras arquitetônicas para garantir a acessibilidade, cumpro a lei de cotas e reúno meus funcionários para uma oficina sobre inclusão, independente de ser apenas para não receber multas, as chances de eu começar a ter condutas mais inclusivas aumenta, pois precisarei equilibrar cognitivamente meu discurso com minhas atitudes.

No contexto empresarial, o psicólogo pode atuar nos setores de recursos humanos, desde a sensibilização dos gerentes para a importância da contratação de pessoas com deficiência, que apresentem potencial para o compromisso social, o que reflete em uma imagem positiva no mercado de trabalho, além de contribuir para uma sociedade mais inclusiva, bem como sobre as potencialidades das pessoas com deficiência, singulares a cada sujeito e que podem agregar valores à instituição, pelo próprio convívio com a diversidade. $\mathrm{O}$ psicólogo pode colaborar no processo de seleção, clarear critérios para a contratação de pessoas com deficiência, condizentes com suas possibilidades e articulados as demandas dos cargos disponíveis, além do treinamento e acompanhamento destes sujeitos em suas funções.

As ações do psicólogo do trabalho, além de enfocarem o sujeito em questão, já apontadas anteriormente, podem englobar os colegas de trabalho, visando transformar suas concepções e atitudes sociais com as estratégias já citadas, promovendo interações mais positivas no ambiente de trabalho. O modo como a deficiência é concebida pelos gestores e colegas de trabalho é um aspecto essencial para a compreensão da dimensão da diversidade.

Ribeiro e Lima (2010) destacaram a necessidade de aumentar a compreensão por parte da sociedade sobre a realidade vivida por pessoas com deficiência para que possam ser acolhidas e tratadas como sujeitos capazes de se desenvolver e de produzir. Carvalho-Freitas et al. (2010) verificaram que as pessoas com deficiência assumem comportamentos mais proativos no ambiente laboral quando percebem que as organizações desenvolvem ações de socialização e adequação. Os autores ainda apresentaram sugestões de normas e procedimentos práticos a serem adotados com este fim, como: (a) critérios de seleção que atentem para as potencialidades das pessoas com deficiência, (b) flexibilidade da organização em fazer as adaptações necessárias para trabalhar com as diferenças, (c) sensibilização das chefias e colegas de trabalho, (d) exposição formalizada dessas pessoas aos valores da organização por meio de treinamentos e acompanhamentos, (e) disponibilização de informações claras sobre a expectativa em relação às atividades a serem desenvolvidas, aos resultados e possibilidades de crescimento, entre outros.

Percebe-se a importância de articulação entre as empresas e as instituições especializadas ou centros de qualificação profissional de pessoas com deficiência para que se conheçam e clareiem as demandas do mercado e as possibilidades dos candidatos às vagas em questão, bem como sejam planejados processos de adaptação e transformações necessárias à inclusão. A mediação desta relação entre estes órgãos também pode contar com a colaboração do profissional psicólogo.

\section{REFERÊNCIAS}

Barbosa, M. A. M., Balieiro, M. M. F. G., \& Pettengill, M. A. M. (2012). Cuidado centrado na família no contexto da criança com deficiência e sua família: Uma análise reflexiva. Texto e Contexto em Enfermagem, 21(1), 194-9. doi: 10.1590/S010407072012000100022

Bittencourt, Z. Z. L. C., \& Fonseca, A. M. R. (2011). Percepções de pessoas com baixa visão sobre seu retorno ao mercado de trabalho. Paidéia (Ribeirão Preto), 21(49), 187-195. doi: 10.1590/S0103-863X2011000200006

Campos, J. A. P. P. (2006). Programa de habilidades sociais em situação natural de trabalho de pessoas com deficiência: Análise dos efeitos (Tese de doutorado). Recuperado de http://www.bdtd.ufscar.br/htdocs/tedeSimplificado//tde_busca/arquivo. php?codArquivo $=1853$

Carvalho-Freitas, M. N., Toledo, I., Nepomuceno, M., Suzano, J., \& Almeida, L. (2010). Socialização organizacional de pessoas com deficiência. Revista Administração de Empresas, 50(3), 264-275. doi: http://dx.doi.org/10.1590/S003475902010000300003 
Coelho, C. M. (2009). Trabalhadores com deficiência: Vivência subjetiva e realidade de trabalho (Dissertação de mestrado). Recuperado de http://www.dominiopublico.gov.br/pesquisa/DetalheObraForm.do?select_action=\&co_obra=167765

Cordeiro, D. R. C. L. (2013). A Inclusão de pessoas com deficiência na rede regular de educação profissional (Dissertação de mestrado). Recuperado de http://repositorio.unesp.br/bitstream/handle/11449/91207/cordeiro_drcl_me_mar. pdf? sequence $=1$ \&isAllowed $=y$.

Dejours, C. (1991). A Loucura do trabalho: Estudo de psicodinâmica do trabalho. São Paulo: Cortez.

Del Prette, Z. A. P., \& Del Prette, A. (1999). Psicologia das habilidades sociais: Terapia e educação. Petrópolis, RJ: Vozes.

Gomes, J. F. B. (2009). Contribuições da categoria trabalho na formação da identidade da pessoa com deficiência (Dissertação de mestrado). Recuperado de http://www.pucminas.br/documentos/dissertacao_jaqueline_fiqueiredo.pdf

Hansel, T. D. (2009). A Empregabilidade de pessoas com deficiências: Possibilidades e limitações. (Monografia de especialização). Recuperado de http://bento.ifrs.edu.br/site/midias/arquivos/201007111045971tania_dubou.pdf

Instituto Brasileiro de Geografia e Estatística. (2010). Pesquisa nacional por amostra de domicílios. Recuperado de http://www. ibge.gov.br/home/estatistica/populacao

Instituto Brasileiro de Geografia e Estatística. (2015). Pesquisa mensal de emprego. Recuperado de http://ibge.gov.br/home/ estatistica/indicadores/trabalhoerendimento/pme_nova

Leão, M. A. B. G., \& Silva, L. S. (2012). Vivências de trabalhadores com deficiência: Uma análise à luz da psicodinâmica do trabalho. Revista Brasileira de Saúde Ocupacional, 37(125), 159-169. doi: 10.1590/S0303-76572012000100019

Meletti, S. M. F. (2001). O significado do processo de profissionalização para o indivíduo com deficiência mental. Revista Brasileira de Educação Especial, 7(1), 77-90.

Ministério do Trabalho e Emprego (2007). A inclusão de pessoas com deficiência no mercado de trabalho (2a ed.). Brasília: MTE, SIT.

Nascimento, E. S., \& Miranda, T. G. (2007). O trabalho e a profissionalização das pessoas com deficiência. Revista Faced, 12, 169-184.

Omote, S. (1990). Aparência e competência em educação especial. Temas em Educação Especial, 1, 11-26.

Omote, S., Oliveira, A. A. S., Baleotti, L. R., \& Martins, S. E. S. O. (2005). Mudança de atitudes sociais em relação à inclusão. Paidéia (Ribeirão Preto), 15(32), 387-398. doi: 10.1590/S0103-863X2005000300008

Pereira, A. C. C., \&Passerino, L. (2012). Um estudo sobre o perfil dos empregados com deficiência em uma organização. Revista Brasileira de Educação Especial, 18(2), 245-264. doi: 10.1590/S1413-65382012000200006

Pires, A. B. M., Bonfim, D., \& Bianchi, L. C. A. P. (2007). Inclusão social da pessoa com Síndrome de Down: Uma questão de profissionalização. Arquivos de Ciências da Saúde, 14(4), 203-10.

Ribeiro, R. P. D., \&Lima, M. E. A. (2010). O trabalho do deficiente como fator de desenvolvimento. Cadernos de Psicologia Social do Trabalho, 13(2), 195-207.

Sassaki, R. K. (2006). Educação profissional: Desenvolvendo habilidades e competências. In Ensaios pedagógicos (pp. 95-108). Brasília: Ministério da Educação, Secretaria de Educação Especial.

Souza-Silva, J. R., Diegues, D., \& Carvalho, S. G. (2012). Trabalho e deficiência: Reflexões sobre as dificuldades da inclusão social. Cadernos de Pós-Graduação em Distúrbios do Desenvolvimento, 12(1), 27-33.

Tanaka, E. D. O., \& Manzini, E. J. (2005). O que os empregadores pensam sobre o trabalho da pessoa com deficiência? Revista Brasileira de Educação Especial, 11(2), 273-294. doi: 10.1590/\$1413-65382005000200008

Tette, R. P. G., Carvalho-Freitas, M. N., \& Oliveira, M. S. (2013). Deficiência e trabalho: Relações entre significado do trabalho e percepção de suporte social e organizacional. Anais do Encontro da Associação Nacional de Pós-graduação e Pesquisa em Administração. Rio de Janeiro: ANPAD.

Toldrá, R. C., Marques, C. B., \& Brunello, M. I. B. (2010). Desafios para a inclusão no mercado de trabalho de pessoas com deficiência intelectual: Experiências em construção. Revista de Terapia Ocupacional da Universidade de São Paulo, 21(2), 158-165. doi:10.11606/issn.2238-6149.v21i2p158-165

Violante, R. R., \& Leite, L. P. (2011). A empregabilidade das pessoas com deficiência: Uma análise da inclusão social no mercado de trabalho do município de Bauru, SP. Cadernos de Psicologia Social do Trabalho, 14(1), 73-91. 